\title{
Variation in the intensity of inbreeding depression among successive life-cycle stages and generations in gynodioecious Silene vulgaris (Caryophyllaceae)
}

\author{
M. GLAETTLI* \& J. GOUDET $\dagger$ \\ *Department of Botany, University of Toronto, Toronto, ON, Canada \\ $\dagger$ †épartement d'Ecologie et d'Evolution, Bâtiment de Biologie, Université de Lausanne, Dorigny, Switzerland
}

\section{Keywords:}

inbreeding depression;

gynodioecy;

late life-cycle stages;

Silene vulgaris.

\begin{abstract}
Inbreeding depression is one of the hypotheses explaining the maintenance of females within gynodioecious plant populations. However, the measurement of fitness components in selfed and outcrossed progeny depends on life-cycle stage and the history of inbreeding. Comparative data indicate that strong inbreeding depression is more likely to occur at later life-cycle stages. We used hermaphrodite individuals of Silene vulgaris originating from three populations located in different valleys in the Swiss Alps to investigate the effect of two generations of self- and cross-fertilization on fitness components among successive stages of the life cycle in a glasshouse experiment. We detected significant inbreeding depression for most life-cycle stages including: the number of viable and aborted seeds per fruit, probability of germination, above ground biomass, probability of flowering, number of flowers per plant, flower size and pollen viability. Overall, the intensity of inbreeding depression increased among successive stages of the life cycle and cumulative inbreeding depression was significantly stronger in the first generation $(\delta \approx 0.5)$ compared with the second generation $(\delta \approx 0.35)$. We found no evidence for synergistic epistasis in our experiment. Our finding of more intense inbreeding depression during later stages of the life cycle may help to explain the maintenance of females in gynodioecious populations of $S$. vulgaris because purging of genetic load is less likely to occur.
\end{abstract}

\section{Introduction}

Gynodioecy is a sexual polymorphism characterized by the co-occurrence of females and hermaphrodites within populations (Darwin, 1877; Lewis, 1941; Lloyd, 1976; Couvet et al., 1998; Shykoff et al., 2003). Inbreeding depression, the fitness reduction of inbred relative to outbred individuals (Lande \& Schemske, 1985; Charlesworth $\&$ Charlesworth, 1987) is commonly invoked to explain the maintenance of females within gynodioecious populations (reviewed in Charlesworth, 1999). The intensity of inbreeding depression required to maintain gynodioecy depends on the genetics of sex determination. To maintain gynodioecy with either nucleo-cytoplasmic or cytoplasmic sex determination, females need only to have a slight fertility advantage over hermaphrodites;

Correspondence: M. Glaettli, Department of Botany, University of Toronto, 25 Willcocks Street, Toronto, M5S 3B2 ON, Canada.

Tel.: 416978 5603; fax: 416978 5878; e-mail: glaettli@botany.

utoronto.ca whereas if sex determination is nuclear, a two-fold advantage of females relative to hermaphrodites is required (Lewis, 1941; Charlesworth \& Ganders, 1979). Empirical evidence indicates that in several gynodioecious species, selfing and inbreeding depression appears to be sufficient to explain the maintenance of females (Kesseli \& Jain, 1984; Kohn \& Biardi, 1995; Sakai et al., 1997; Mutikainen \& Delph, 1998). However, estimates of inbreeding depression vary considerably depending on life-cycle stages and on the degree of inbreeding in populations. Therefore, these influences should be assessed in determining the role of inbreeding depression in the maintenance of gynodioecy.

Gynodioecy has been investigated in some detail in the European perennial herb Silene vulgaris (Caryophyllaceae) where sex determination is under nucleocytoplasmic control (Charlesworth \& Laporte, 1998). Experiments in this species comparing the fitness of selfed and outcrossed pollinations during one generation focused only on early life-cycle stages (Jolls $\delta$ 
Chenier, 1989; Pettersson, 1992). However, Emery \& McCauley (2002) working with introduced North American populations of $S$. vulgaris assessed inbreeding depression for survivorship to flowering and detected more intense inbreeding depression than during early life-cycle stages. Their result is consistent with comparative evidence from a species survey indicating that late life-cycle stages generally exhibit higher levels of inbreeding depression (Husband \& Schemske, 1996). The expression of inbreeding depression later in the life cycle is significant because it is thought to be the consequence of many mildly deleterious alleles, which should reduce the efficacy of purging of the genetic load. This could have important implications for the maintenance of gynodioecy because limited purging will maintain genetic load and conditions favouring outbreeding advantage in females. Accurate assessment of inbreeding depression in gynodioecious species should therefore include several life-cycle stages and comparisons between generations differing in inbreeding coefficient.

Investigations involving several generations of inbreeding have also been used to detect whether interactions between loci (epistasis) influences levels of inbreeding depression (Willis, 1993; Carr \& Dudash, 1997; Koelewijn, 1998). If deleterious mutations act independently, the fitness effects of different loci are multiplicative and this should result in a linear relation between the log of fitness and the inbreeding coefficient (Crow \& Kimura, 1970). However, when deleterious mutations interact synergistically the log of fitness declines at a greater than linear rate with inbreeding. Synergistic epistasis will increase the intensity of inbreeding depression over that expected if mutations act independently (Charlesworth et al., 1991). Therefore, epistasis influences the rate at which the genetic load can be purged from populations and is of considerable significance for the evolution and maintenance of sexual systems (Charlesworth, 1990).

In this study we investigate the effect of two consecutive generations of self- and cross-pollinations on hermaphrodites of gynodioecious $S$. vulgaris. We consider fitness from self- vs. cross-pollination in the first generation and from three levels of inbreeding in the second generation $(F \geq 0$ for all cross-pollinations, $F \geq 0.5$ for one generation of self-pollinations and, $F \geq 0.75$ for two successive generations of self-pollinations). To quantify inbreeding depression we sampled families of $S$. vulgaris from three different valleys in the western Swiss Alps and used these to assess fitness differences between selfed and outcrossed progeny for successive life-history traits. Our investigation had three main goals: (i) to determine the magnitude of inbreeding among successive stages of the life cycle; (ii) to compare cumulative inbreeding depression between two generations differing in their inbreeding coefficient; (iii) to investigate the extent to which synergistic epistasis is evident in $S$. vulgaris. We discuss the implications of our results for the maintenance of gynodioecy in this species.

\section{Methods}

\section{Study species}

Silene vulgaris (Moench) Garke is a gynodioecious herbaceous short-lived perennial, weedy plant distributed in the Holarctic. Hermaphrodites are self-compatible and strongly protandrous: stamens dehisce within 2 days and then stigmas develop and are receptive for 3 days. Autonomous self-pollination is infrequent, as reported by Pettersson (1992) who found less than 5\% seed set resulting from intra-floral selfing. However, hermaphrodites have the potential for self-fertilization through geitonogamous pollen transfer as (i) the number of flowers open daily can be large (up to 100/day), (b) pollinators (Noctuidae moths) forage within restricted areas and often within a plant (Pettersson, 1992; M. Glaettli, personal observation). Each fruit is a capsule containing up to 100 seeds that disperse through gravity. Thus, overall pollen and seed dispersal is limited which provides opportunities for inbreeding resulting in strong population structure (McCauley, 1998).

\section{Field collection and plant rearing}

In September 2000, we collected mature fruits from different maternal parents of $S$. vulgaris in three different valleys of the Western Swiss Alps: Mont d'Or (MO: $570^{\circ} 23^{\prime} 20.4^{\prime \prime} \mathrm{N} / 137^{\circ} 24^{\prime} 57$. 6"E, altitude: $\left.1880 \mathrm{~m}\right)$, Dent de Jaman (DJ: $546^{\circ} 23^{\prime} 52.8^{\prime \prime} \mathrm{N} / 144^{\circ} 23^{\prime} 20.4^{\prime \prime} \mathrm{E}$, altitude: $1543 \mathrm{~m}$ ) and Val Ferret (VF: $574^{\circ} 45^{\prime} 39.6^{\prime \prime} \mathrm{N} / 084^{\circ} 50^{\prime} 38$. $4^{\prime \prime} \mathrm{E}$, altitude: $1895 \mathrm{~m}$ ). We subsequently refer to each valley (MO, DJ, VF) as a 'population'. Mont d'Or was a large population of approximately 500 individuals where sex ratio (i.e. the proportion of hermaphrodites) was 0.8 . The VF and DJ populations were each composed of 10 different sub-populations distributed over $2 \mathrm{~km}$. The size of sub-populations varied from 10 to 50 individuals and from 50 to 100 individuals for DJ and VF, respectively. Within the DJ and VF valleys, sub-population sex ratios ranged from 0.8 to 1.0 .

In March 2001, we sowed the collected seeds in a glasshouse at the University of Lausanne using Jiffy pots (Ø $5 \mathrm{~cm}$ ) (natural light conditions, $18-20^{\circ} \mathrm{C}, 50-60 \%$ relative humidity). In April 2001, we transplanted seedlings into larger pots (Ø $15 \mathrm{~cm}$; substrate: $50 \%$ peat $/ 50 \%$ clay soil). At flowering, we randomly chose 60 hermaphrodites (20 per population), each originating from a different hermaphroditic maternal plant in the field.

\section{Experimental design and fitness components}

We measured fitness components among life-cycle stages and these were classified into 'seed traits', 'progeny traits' 
(from germination to maturity) and 'reproductive traits' (Fig. 1).

\section{Generation $F_{1}$}

We performed self- $(S)$ and cross-pollinations $(C)$ of all hermaphrodites, which allowed to control for maternal effects (Lynch, 1988). For each hermaphrodite (subsequently referred to as a family), we emasculated 12 flowers and enclosed each in a transparent philatelist envelope. Two flowers were not hand pollinated to assess the efficiency of envelopes in preventing uncontrolled pollinations. None of the unpollinated flowers produced seeds. Five flowers were self-pollinated $(S)$ and five flowers were cross-pollinated $(C)$ with five different pollen donors from the same population (Fig. 1). We saturated flowers with pollen to limit the effects of different pollen loads and/or pollen viability. When capsules were mature (July 2001) we measured the following 'seed traits': fruit set, number of viable seeds per fruit, number of aborted seeds per fruit (shrunken seeds that did not germinate) and the mean weight of viable seeds estimated as the total weight of viable seeds divided by the number of viable seeds within a fruit (Fig. 1).

In September 2001, we sowed seeds from half of the families (10 families/population) into Jiffy pots. For each family we planted 16 seeds from each pollination treatment ( $S$ vs. $C$ ) and checked for germination and flowering daily. In December 2001, we sowed seeds (16 S and $16 \mathrm{C}$ ) from the 30 remaining families (10 families/ population) and censored them in the same way. At this point we installed artificial light thus glasshouse condi-

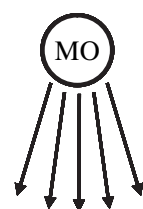

20

hermaphrodites

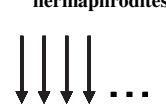

For each hermaphrodite:

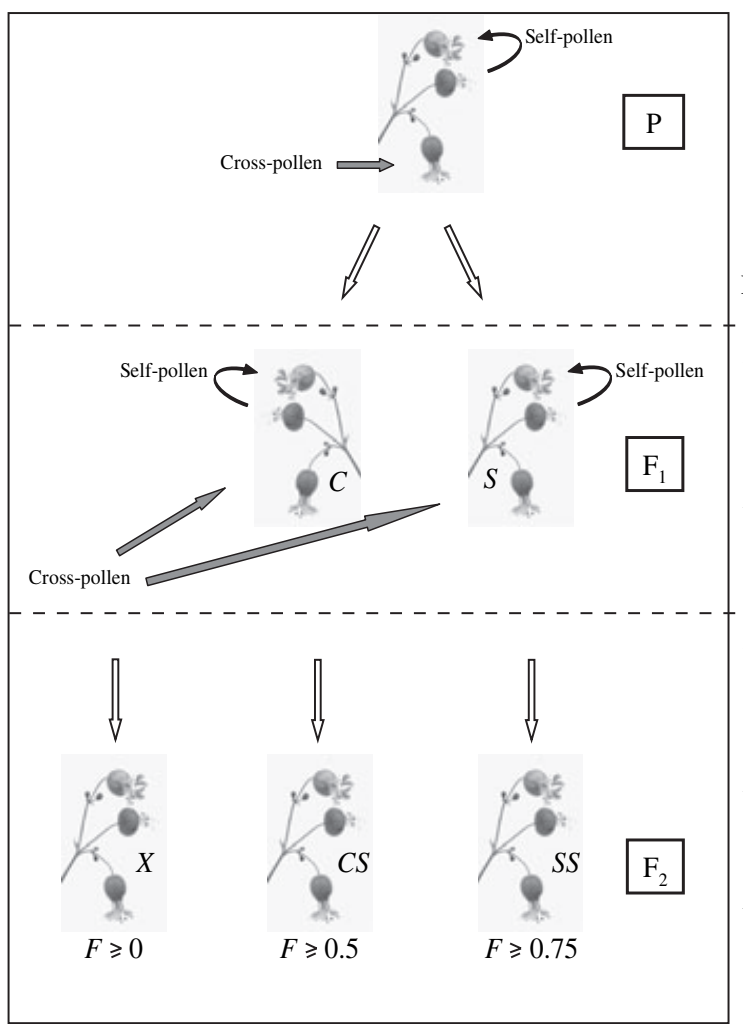

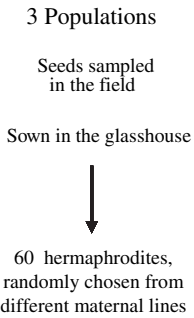

randomly chosen from
different maternal lines

Fitness components:

Seed traits:

- Fruit set

- Number of viable seeds/fruit

- Number of aborted seeds/fruit

- Mean weight of viable seeds

Progeny traits:

- Probability of germination

- Probability of flowering

Seed traits:

- Fruit set

- Number of viable seeds/fruit

- Number of aborted seeds/fruit

- Mean weight of viable seeds

Progeny traits:

- Probability of germination

- Above ground dry biomass

- Probability of flowering

Reproductive traits:

- Number of flowers/plant

- Flower size

- Number of pollen grains/stamen

- Pollen viability

Fig. 1 Scheme of sampling, design of inbreeding depression experiment and measured fitness traits in Silene vulgaris. 
tions were: $15 \mathrm{~h}$ light $/ 9 \mathrm{~h}$ dark, $18-20^{\circ} \mathrm{C}, \quad 50-60 \%$ relative humidity. We assessed fitness components for 'progeny traits' as the probability of germination and the probability of flowering (Fig. 1). The estimate of probability of flowering included plant survival from germination to flowering. Survivorship between germination and flowering was $90 \pm 3 \%$ and $97 \pm 1 \%$ for inbred and outbred plants for both generations.

\section{Generation $F_{2}$}

In March 2003, we produced a second generation $\left(F_{2}\right)$ through self- and cross-pollinations of $S$ and $C$ hermaphrodites from generation $F_{1}$ (Fig. 1). We randomly chose one $S$-hermaphrodite and one $C$-hermaphrodite from each family. Selfing of $S$ - and $C$-hermaphrodites resulted in $S S(F \geq 0.75)$ and $C S(F \geq 0.5)$ progeny, respectively and, cross-pollinations of $S$ and $C$ plants were denominated $X(F \geq 0)$ (Fig. 1). The inbreeding coefficient $(F)$ can be greater or equal to $0,0.5$ or 0.75 depending on the level of inbreeding in populations sampled in the field. However, this does not alter interpretation of our results because comparisons between inbreeding levels were subsequently assessed within families.

Large inbreeding depression in generation $F_{1}$ resulted in the loss of some families during the experiment. First, some $S$ plants ( $3 \%$ of families) from the $\mathrm{F}_{1}$ did not reach maturity and thus the whole family was removed from the experiment. Second, delayed flowering in $S$ plants (compared with $C$ plants) sometimes prevented crosspollinations from being conducted. Thus, 45 families (12, 19 and 14 for MO, VF and DJ, respectively) remained in the experiment to estimate fitness in 'seed traits' as in generation $\mathrm{F}_{1}$ (Fig. 1).

In August 2003 we removed families in which only one level of inbreeding $(F)$ produced viable seeds resulting in 30 families $(8,12$ and 10 for MO, VF and DJ, respectively). We randomly chose 20 seeds from the 0.5 and 0.75 inbreeding levels $(F)$ and 100-200 seeds (i.e. 5-10 different sires $\times 20$ seeds) for cross-pollinations $(F \geq 0)$. We assessed 'progeny traits' as: probability of germination, aboveground dry biomass and probability of flowering. We used a sub-sample of plants just before maturity (2-3 plants/level of inbreeding), dried plants for 7 days at $60^{\circ} \mathrm{C}$ and then weighted them to the nearest $0.1 \mathrm{mg}$ to assess aboveground dry biomass.

Fitness components for 'reproductive traits' included: the number of flowers per plant, flower size, pollen quantity and pollen viability. We counted the number of flowers per plant on each plant 21 days after its first flower opened. To assess flower size we randomly sampled 12 flowers per family: two flowers $\times$ two plants $\times$ three levels of inbreeding $(F)$. To ensure that all flowers were in the same development stage we marked flowers the first day of anthesis and harvested their petals 2 days later between 10:30 AM and 2:00 PM. We took a picture of two petals per flower and measured their area with the help of UtHSCSA IMAGE TOOL 3.00
Software (http://ddsdx.uthscsa.edu/dig/itdesc.html). We considered flower size as the petal area average for each level of inbreeding. We assessed male reproductive output as the number of pollen grains and the proportion of viable pollen grains per stamen. In each family, we sampled two stamens (one for pollen grain number and one for pollen viability) from two flowers per plant and two plants per level of inbreeding $(F)$. To assess number of pollen grains per stamen and pollen viability we followed methods outlined in Atlan et al. (1992), Dafni (1992) and Gigord et al. (1999). We used microscopy to estimate the number of pollen grains per stamen and pollen viability. We assessed the proportion of viable pollen grains within a sample of about 300 pollen grains (range: 94-934).

\section{Cumulative fitness}

In generation $\mathrm{F}_{1}$, cumulative fitness was the product of (i) fruit set, (ii) the number of viable seeds per fruit, (iii) the probability of germination and (iv) the probability of flowering. As, we assessed more fitness components in generation $\mathrm{F}_{2}$, we computed two different coefficients of cumulative fitness. To allow comparisons with generation $F_{1}$, cumulative fitness $A$ was the product of (i) fruit set, (ii) the number of viable seeds per fruit, (iii) probability of germination and (iv) probability of flowering. To account for all fitness traits measured in generation $\mathrm{F}_{2}$, cumulative fitness $\mathrm{B}$ was the product of (i) fruit set, (ii) number of viable seeds per fruit, (iii) probability of germination, (iv) probability of flowering, ( $\mathrm{v}$ ) number of flowers per plant, (vi) number of pollen grains per stamen and (vii) pollen viability.

\section{Data analysis}

Fitness components

In generation $\mathrm{F}_{1}$, we used two-tailed paired $t$-tests or Wilcoxon signed rank tests to detect differences between pollination treatments within families. In generation $F_{2}$, we analysed all fitness components using two models of Anova. We used a repeated-measure Anova to compare levels of inbreeding $(\alpha)$ within families (A): $Y_{i j k}=$ $\mu+A_{i}+\alpha_{j}+(\alpha A)_{i j}+\varepsilon_{i j k}$ (model 1). Family was random and level of inbreeding was a fixed effect. We used a second mixed Anova with nested effects (model 2: $Y_{i j k l}=$ $\left.\mu+B_{i}+A_{i j}+\alpha_{k}+(\alpha B)_{i k}+(\alpha A)_{i j k}+\varepsilon_{i j k l}\right)$ to test for population (B), family (A) and interactions with levels of inbreeding $(\alpha)$. Level of inbreeding was as fixed effect whereas population and family were random and family was nested within populations. Because transformation of data did not help to satisfy anova conditions, we performed randomization tests (1000 permutations) on mean squares (Manly, 1997). If less than 5\% of permutations give a larger mean square than the one obtained with the observed data, the tested effect is considered as significant. The schemes of randomization were the following: we tested levels of inbreeding by randomizing 
levels of inbreeding within families (model 1). If significant, we subsequently performed the following planned comparisons: outbred $(F \geq 0)$ vs. inbred $(F \geq 0.5$ and $F \geq 0.75)$ and between inbred plants $(F \geq 0.5$ vs. $F \geq 0.75)$. For population effect, we randomized families among populations. For family effect, we randomized individuals among families within levels of inbreeding for each population. We tested the interaction family $\times$ levels of inbreeding as the permutation of data within populations and, finally we tested population $\times$ levels of inbreeding interaction as the randomization of whole families between populations combined with the permutation of inbreeding levels within families. Statistical analyses were performed with the statistical package $\mathrm{R}$ (Version 1.8.1) (R Development Core Team, 2003).

\section{Inbreeding depression coefficients}

In generation $\mathrm{F}_{1}$, we estimated inbreeding depression $\delta$ as $\left(w_{o}-w_{s}\right) / w_{\max }$, where $w_{o}$ and $w_{s}$ are the fitness of outcrossed and selfed progeny, respectively and $w_{\max }$ is the maximum of both (Ågren \& Schemske, 1993). This estimate of inbreeding depression varies between -1 and 1 ; where -1 implies zero fitness for outcrossed plants and, 1 zero fitness for selfed plants.

We computed an inbreeding depression coefficient $\delta_{\mathrm{F}}$ for each family and its mean $\bar{\delta}_{F}$ (family mean inbreeding depression) for each population using the following formula (Johnston \& Schoen, 1994) ( $n$ is the number of families/population):

$$
\bar{\delta}_{\mathrm{F}}=\frac{1}{n} \sum \frac{W_{o i}-W_{s i}}{W_{\max i}}
$$

Family inbreeding depression estimates $\left(\delta_{\mathrm{F}}\right)$ allowed us to test for correlations among life-cycle traits within generations and between generations when possible (Pearson's or Spearman correlations). Population inbreeding depression $\left(\delta_{\mathrm{P}}\right)$ is a single measure of inbreeding depression per populations using the mean fitness of selfed and outcrossed progeny across all families. Population inbreeding depression $\left(\delta_{\mathrm{P}}\right)$, is generally considered as a better estimate of inbreeding depression than mean family inbreeding depression $\left(\bar{\delta}_{\mathrm{F}}\right)$ because large differences between pollination treatments among families is more likely to bias $\bar{\delta}_{\mathrm{F}}$ than $\delta_{\mathrm{P}}$ (Johnston $\&$ Schoen, 1994). However, population inbreeding depression $\left(\delta_{\mathrm{P}}\right)$ was always within the confidence interval of mean family inbreeding depression $\left(\bar{\delta}_{\mathrm{F}}\right)$ for any fitness components. Thus, we subsequently only considered mean family inbreeding depression $\left(\bar{\delta}_{\mathrm{F}}\right)$. Since, we generally did not find significant differences between $F \geq 0.5$ and $F \geq 0.75$ in generation $F_{2}$ (see results) we pooled inbred plants together and calculated estimates of inbreeding depression at the family level $\left(\delta_{\mathrm{F}}\right)$.

\section{Epistasis}

We tested for the nonlinearity of the relation between the log of fitness component and inbreeding level using a polynomial regression. A significant negative quadratic relationship resulting in a sharper decrease between $F \geq 0.5$ and $F \geq 0.75$ than between $F \geq 0$ and $F \geq 0.5$ is indicative of synergistic epistasis and a significant positive quadratic coefficient can be due either to diminishing epistasis (antagonistic) and/or purging of partially deleterious alleles (Dudash et al., 1997; Koelewijn, 1998).

\section{Results}

\section{Fitness components}

Generation $F_{1}$

Inbreeding depression was evident after one generation of self-fertilization in each of the three populations. We found larger differences between self- and cross-pollination in late life-cycle stages compared with early ones (Table 1, Fig. 2). In 'seed traits', two traits of four were significantly affected by inbreeding (number of viable and aborted seeds per fruit). Cross-pollinations produced $17 \%$ more viable seeds and $90 \%$ less aborted seeds per fruit than self-pollinations. Mean weight of viable seeds per fruit was $4.5 \%$ lighter for selfed compared with outcrossed progeny; however this difference was only marginally significant. Finally, fruit set was not significantly different between pollination treatments (Table 1).

In 'progeny traits' inbreeding affected all measured traits: probability of germination and probability of flowering were respectively $30 \%$ and $41 \%$ lower in selfed compared with outcrossed progeny (Table 1, Fig. 2). Numbers of days to germination and to flowering were also significantly affected by inbreeding. Selfed seeds took more time to germinate (mean \pm SE) than outcrossed progeny $(13.1 \pm 0.8$ and $10.8 \pm 0.5$ days, respectively); such were the number of days to flowering $($ mean \pm SE) $: 96.7 \pm 2.4$ and $89.1 \pm 1.9$ for progeny from self- and cross-pollinations, respectively.

\section{Generation $F_{2}$}

In the second generation $\left(\mathrm{F}_{2}\right)$, the effects of self-pollination on fitness related traits were similar to the first generation $\left(F_{1}\right)$. Number of aborted seeds per fruit, probability of germination and probability of flowering decreased significantly with inbreeding whereas number of viable seeds per fruit was not significantly different between levels of inbreeding (Tables 2 and 3). Within the additional traits measured in generation $\mathrm{F}_{2}$, only number of pollen grains per stamen was not significantly different between the inbreeding levels. All other traits: aboveground dry biomass, number of flowers per plant, flower size and pollen viability decreased significantly with inbreeding (Tables 2 and 3, Fig. 3). When inbreeding affected fitness traits, plants from cross-pollinations $(F \geq 0)$ always outperformed inbred progeny $(F \geq 0.5$ and $F \geq 0.75)$ but no significant difference was detected within inbred plants $(F \geq 0.5$ vs. $F \geq 0.75)$. Only prob- 
Table 1 Mean and standard error (SE) of generation $\mathrm{F}_{1}$ fitness traits, measured at different stages along the life cycle for self- and crosspollinations in Silene vulgaris ( $n=$ sample size). Comparisons between pollination treatments within the maternal parents are computed with paired test.

\begin{tabular}{|c|c|c|c|c|c|c|c|}
\hline \multirow[b]{3}{*}{ Traits } & \multirow[b]{3}{*}{$n$} & \multicolumn{4}{|c|}{ Pollination treatments } & \multirow[b]{3}{*}{$P$-value } & \multirow[b]{3}{*}{ Test } \\
\hline & & \multicolumn{2}{|l|}{ Outcrossed } & \multicolumn{2}{|l|}{ Selfed } & & \\
\hline & & Mean & SE & Mean & SE & & \\
\hline Fruit set & 61 & 0.66 & 0.04 & 0.68 & 0.04 & NS & Wilcoxon \\
\hline Number of viable seeds/fruit & 61 & 31.92 & 2.75 & 27.27 & 2.35 & * & Paired $t$-test \\
\hline Weight of seeds (mg) & 61 & 8.50E-04 & 3.50E-05 & $8.12 \mathrm{E}-04$ & $5.50 \mathrm{E}-05$ & $\dagger$ & Wilcoxon \\
\hline Number of aborted seeds/fruit & 61 & 2.65 & 0.42 & 5.04 & 0.61 & *** & Wilcoxon \\
\hline Probability of germination & 57 & 0.74 & 0.03 & 0.57 & 0.04 & 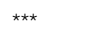 & Wilcoxon \\
\hline Probability of flowering & 55 & 0.9 & 0.02 & 0.64 & 0.04 & 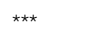 & Wilcoxon \\
\hline
\end{tabular}

NS, $P>0.05 ; \dagger 0.05<P<0.1 ; * P \leq 0.05 ; * * P \leq 0.01 ; * * * P \leq 0.001$.

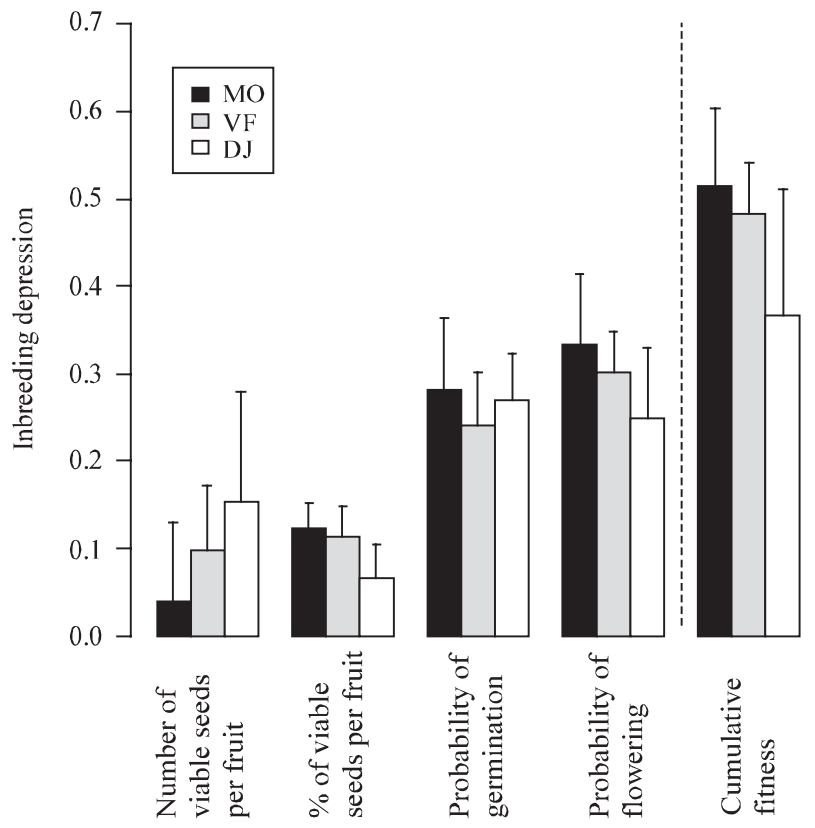

Fig. 2 Means of family inbreeding depression $( \pm$ SE) in Silene vulgaris for successive life-cycle stages and cumulative fitness estimates in generation $\mathrm{F}_{1}$.

ability of germination showed a significant decrease between seeds from one and two successive generations of self-fertilization (Table 2).

We detected significant variation among populations in all 'seed traits', number of flowers per plant and flower size. The significant population effect was always associated with a significant interaction between population and levels of inbreeding (Table 3, Fig. 3), indicating that when populations differed from each other, they also differed in their response to levels of inbreeding. Family variation was also significant for several fitness traits indicating that intrinsic fitness value was different between families (Table 3).

\section{Inbreeding depression}

In both generations inbreeding depression for 'seed traits' was lower than for 'progeny' and 'reproductive traits'. Thus, the fitness difference between outcrossed and selfed progeny increased among successive stages of the life cycle (Figs 2 and 3). We did not observe any significant correlations of 'family inbreeding depression' $\left(\delta_{\mathrm{F}}\right)$ between the different life-cycle traits.

Estimates of cumulative inbreeding depression ranged from 0.46 to 0.56 for generation $\mathrm{F}_{1}$ (Fig. 2) and from 0.10 to 0.45 for generation $\mathrm{F}_{2}$ (cumulative fitness $\mathrm{A}$ ). When additional 'reproductive traits' were taken into account cumulative fitness (B) ranged from 0.46 to 0.74 (Fig. 3).

A comparison of inbreeding depression between generation $F_{1}$ and $F_{2}$ indicated that for all fitness traits, differences between inbred and outbred progeny were always larger in the $F_{1}$ than in the $F_{2}$ (Fig. 4). However, only cumulative fitness was significantly lower for generation $\mathrm{F}_{1} \quad(\delta \approx 0.5)$ than for generation $\mathrm{F}_{2}$ $(\delta \approx 0.35)$ (one-sided paired $t$-test, d.f. $=25, P<0.01)$. We did not observe any significant correlations between 'family inbreeding depression' $\left(\delta_{\mathrm{F}}\right)$ between generations indicating that the deleterious alleles expressed in $\mathrm{F}_{1}$ and $\mathrm{F}_{2}$ were likely different.

\section{Epistasis}

The quadratic term of polynomial regressions between log-transformed fitness components and inbreeding levels $(F)$ were never significantly different from zero. Thus our experiment did not detect epistasis. The power to detect a significant quadratic term given the observed mean difference between inbreeding levels and our sample size was never larger than $40 \%$.

\section{Discussion}

Our study demonstrated pervasive inbreeding depression in three gynodioecious populations of S. vulgaris. Signi- 
Table 2 Mean and standard error (SE) of generation $\mathrm{F}_{2}$ fitness traits measured at different stages along the life cycle for cross-pollinations $(X)$, one generation of self-pollinations (CS) and two consecutive generations of self-pollinations (SS) in Silene vulgaris ( $n=$ sample size).

\begin{tabular}{|c|c|c|c|c|c|c|c|c|}
\hline \multirow[b]{3}{*}{ Traits } & \multirow[b]{3}{*}{$n$} & \multicolumn{6}{|c|}{ Levels of inbreeding } & \multirow[b]{3}{*}{$P$-value } \\
\hline & & \multicolumn{2}{|l|}{$X(F=0)$} & \multicolumn{2}{|l|}{$C S(F=0.5)$} & \multicolumn{2}{|l|}{$S S(F=0.75)$} & \\
\hline & & Mean & SE & Mean & SE & Mean & SE & \\
\hline Fruit set & 45 & 0.93 & 0.01 & 0.79 & 0.05 & 0.86 & 0.05 & NS \\
\hline Number of viable seeds/fruit & 45 & 43.38 & 1.07 & 43.80 & 4.80 & 39.33 & 3.20 & NS \\
\hline Weight of seeds (mg) & 45 & 1.07E-03 & $1.07 \mathrm{E}-04$ & $1.13 E-03$ & $7.02 \mathrm{E}-05$ & $1.31 \mathrm{E}-03$ & $3.30 \mathrm{E}-04$ & NS \\
\hline Number of aborted seeds/fruit & 45 & $4.86 \dagger$ & 0.35 & $7.00 \ddagger$ & 2.48 & $7.66 \$$ & 2.16 & * \\
\hline Probability of germination & 28 & $0.84 \dagger$ & 0.01 & $0.76 \ddagger$ & 0.04 & $0.64 \S$ & 0.05 & 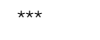 \\
\hline Above ground dry biomass (g) & 27 & $1.64 \dagger$ & 0.07 & $0.91 \ddagger$ & 0.11 & $0.79 \$$ & 0.09 & 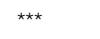 \\
\hline Probability of flowering & 28 & $0.83 \dagger$ & 0.02 & $0.65 \ddagger$ & 0.05 & $0.64 \$$ & 0.05 & 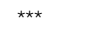 \\
\hline Number of flowers/plant & 28 & $27.55 \dagger$ & 1.53 & $19.28 \ddagger$ & 1.58 & $21.08 \ddagger$ & 2.64 & $\star \star$ \\
\hline Flower size $\left(\mathrm{mm}^{2}\right)$ & 28 & $37.36 \dagger$ & 1.50 & $29.87 \ddagger$ & 1.63 & $25.49 \ddagger$ & 1.82 & $\star \star \star \star ~$ \\
\hline Mean number of pollen grains/stamen & 28 & 462.77 & 49.31 & 291.84 & 46.71 & 349.77 & 44.21 & NS \\
\hline Pollen viability & 28 & $0.87 \dagger$ & 0.01 & $0.62 \ddagger$ & 0.03 & $0.60 \div$ & 0.04 & 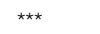 \\
\hline
\end{tabular}

Planned comparisons $X$ vs. (CS and $S S$ ) and CS vs. SS. $\dagger, \ddagger$ $\S$ indicate the results of planned comparisons. NS, $P>0.05 ;{ }^{*} P \leq 0.05 ;{ }^{* *} P \leq 0.01$; $* * * P \leq 0.001$.

ficantly, the magnitude of inbreeding depression increased among successive stages of the life cycle (Figs 2$4)$. Cumulative inbreeding depression (A) ranged between $0.46-0.56$ and between $0.10-0.45$ in generation $F_{1}$ and $\mathrm{F}_{2}$, respectively. However, when additional life-cycle traits were measured in the $\mathrm{F}_{2}$, cumulative inbreeding depression (B) ranged between 0.46 and 0.74 . Fitness was highly depressed when comparing outbred $(F \geq 0)$ and inbred individuals $(F \geq 0.5$ and $F \geq 0.75)$ but no further decrease was detected between inbred plants $(F \geq 0.5$ vs. $F \geq 0.75)$. The quadratic coefficient of the polynomial regression of log-transformed fitness on inbreeding levels $(F)$ was never significantly different from zero, thus we did not detect epistasis. Below we discuss the significance of these results for the maintenance of gynodioecy in $S$. vulgaris.

\section{The intensity of inbreeding depression among life- cycle stages and between generations}

Our results are similar to a previous study conducted over a single generation in $S$. vulgaris (Emery $\&$ McCauley, 2002). These authors studied introduced North American populations of $S$. vulgaris and cumulative inbreeding depression was very similar to our results in generation $\mathrm{F}_{1}(\delta \approx 0.5)$. However, when including later reproductive stages, as we did in generation $\mathrm{F}_{2}$, cumulative inbreeding depression estimates increased up to 0.74 . Thus, estimates of inbreeding depression were clearly increasing along the life-cycle stages (Figs 2-4) and point out how important it is to screen late stages (Willis, 1993; Mayer et al., 1996; Carr \& Dudash, 1997; Melser et al., 1999) to not underestimate lifetime inbreeding depression in $S$. vulgaris.

In this study, we show that in $S$. vulgaris inbreeding affects negatively the number of flowers per plant and flower size. These effects are of significance because they could reduce the potential attraction to pollinators and decrease the fitness of plants. Indeed, floral display and flower size have been shown to influence the attraction of pollinators in several studies (Kobayashi et al., 1997; Vaughton \& Ramsey, 1998; Karron et al., 2004). A previous study of $S$. vulgaris showed that the number of open flowers per plant correlated positively with the number of pollinators attracted (M. Glaettli, unpublished data). Flowers with large petals were more likely to become infected by the fungus Microbotryum violaceum in the related Dianthus silvestris (Shykoff et al., 1997). This fungus places its spores in the anthers of parasitized plants and use pollinators as a dispersing agent. The result of Shykoff et al. (1997) shows that pollinators visited preferentially plants with larger flowers. Therefore, the decrease in number and size of flowers of inbred compared with outbred individuals in S. vulgaris, might reduce their capacity to attract pollinators. Moreover, we detected inbreeding depression in pollen viability. Thus, inbred individuals that might attract pollinators may not be as effective at siring seeds since only $60 \%$ of their pollen grains are viable.

Husband \& Schemske (1996) demonstrated that in both predominantly selfing and outcrossing species levels of inbreeding depression in late stages of the life cycle are similar. This result could indicate that the genetic load at late history stages is due to mildly deleterious mutations that are difficult to purge (Charlesworth et al., 1991). However, cumulative inbreeding depression for selfing species was $43 \%$ of that in outcrossing species and supports the hypothesis that highly deleterious recessive alleles are an important source of inbreeding depression which can be purged with selfing (Charlesworth $\&$ Charlesworth, 1987; Keller \& Waller, 2002). In this study, we show that the intensity of inbreeding depression is lower in $F_{2}$ than in $F_{1}$ for all fitness traits measured 
Table 3 Analyses of variance for the different fitness traits estimated after two consecutive generations of self- and cross-pollinations in Silene vulgaris. Levels of inbreeding is a fixed effect; population and family are random effects; family is nested within population.

\begin{tabular}{|c|c|c|c|c|c|c|c|c|c|c|c|c|}
\hline \multirow[b]{2}{*}{ Source of variation } & \multicolumn{3}{|c|}{ Fruit set } & \multicolumn{3}{|c|}{ Number of seeds/fruit } & \multicolumn{3}{|c|}{$\begin{array}{l}\text { Number of aborted } \\
\text { seeds/fruit }\end{array}$} & \multicolumn{3}{|c|}{$\begin{array}{l}\text { Mean weight of seeds } \\
(\mathrm{mg})\end{array}$} \\
\hline & d.f. & MS & $P$-value & d.f. & MS & $P$-value & d.f. & $M S$ & $P$-value & d.f. & MS & $P$-value \\
\hline \multicolumn{13}{|l|}{ (A) Seed traits } \\
\hline Population & 2 & 1.69 & $0.007^{\star \star}$ & 2 & 679 & $0.016^{*}$ & * & 340 & $0.033^{\star}$ & 2 & 6.70 & 0.368 \\
\hline Levels of inbreeding $(F)$ & 2 & 0.19 & 0.387 & 2 & 54 & 0.567 & 2 & 307 & $0.046^{*}$ & 2 & 0.70 & 0.184 \\
\hline Levels of inbreeding $(F) \times$ population & 4 & 0.60 & $0.001^{* \star *}$ & 4 & 119 & $0.001^{*}$ & *** & 365 & $0.010^{\star}$ & 4 & 0.90 & $0.001^{\star \star \star}$ \\
\hline Levels of inbreeding $(F) \times$ family (population) & 68 & 0.18 & 0.832 & 68 & 75 & 0.499 & 68 & 148 & 0.145 & 51 & 0.90 & 0.220 \\
\hline \multirow[t]{2}{*}{ Error } & 693 & 0.20 & & 692 & 75 & & 694 & 71 & & 463 & 8.50 & \\
\hline & \multicolumn{4}{|c|}{ Probability of germination } & \multicolumn{4}{|c|}{ Above ground dry weight (g) } & \multicolumn{4}{|c|}{ Probability of flowering } \\
\hline Source of variation & \multicolumn{2}{|c|}{ d.f. } & MS & $P$-value & \multicolumn{2}{|r|}{ d.f. } & MS & $P$-value & d.f. & \multicolumn{2}{|c|}{ MS } & $P$-value \\
\hline Population & \multicolumn{2}{|c|}{2} & .22 & 0.306 & \multicolumn{2}{|r|}{2} & 0.49 & 0.661 & 2 & \multicolumn{2}{|c|}{0.40} & 0.103 \\
\hline Levels of inbreeding $(F)$ & \multicolumn{2}{|c|}{2} & .49 & $0.001^{* \star *}$ & \multicolumn{2}{|r|}{2} & 16.01 & $0.001^{\star \star \star}$ & 2 & \multicolumn{2}{|c|}{0.50} & $0.001^{\star \star \star}$ \\
\hline Family (population) & \multicolumn{2}{|c|}{27} & 0.15 & $0.001^{\star \star \star}$ & & 26 & 1.13 & $0.001^{\star \star \star}$ & 27 & & 17 & $0.002^{\star \star}$ \\
\hline Levels of inbreeding $(F) \times$ population & & 4 & 0.02 & 0.308 & & 4 & 2.66 & 0.644 & 4 & & .06 & 0.066 \\
\hline Levels of inbreeding $(F) \times$ family (population) & & & 0.05 & 0.580 & & 44 & 0.62 & 0.620 & 44 & & .05 & 0.904 \\
\hline Error & 19 & & 0.03 & & & 129 & 0.28 & & 123 & & .06 & \\
\hline & Num & er of flo & /ers/plant & Flower & size ( & $\left.\mathrm{mm}^{2}\right)$ & $\begin{array}{l}\text { Numb } \\
\text { stame }\end{array}$ & er of pollen & grains/ & Polle & viabilit & \\
\hline Source of variation & d.f. & MS & $P$-value & d.f. & MS & $P$-value & d.f. & MS & $P$-value & d.f. & $M S$ & $P$-value \\
\hline (C) Reproductive traits & & & & & & & & & & & & \\
\hline Population & 2 & 2753 & $0.008^{\star \star}$ & 2 & 765 & $0.042^{*}$ & 2 & 285919 & 0.628 & 2 & 0.08 & 0.138 \\
\hline Levels of inbreeding $(F)$ & 2 & 937 & $0.008^{\star \star}$ & 2 & 1690 & $0.001^{\star \star \star}$ & 2 & 324155 & 0.158 & 2 & 1.42 & $0.001^{* * *}$ \\
\hline Levels of inbreeding $(F) \times$ family (population) & 44 & 188 & 0.852 & 44 & 94 & 0.852 & 42 & 73586 & 1.000 & 42 & 0.04 & 0.586 \\
\hline Error & 116 & 242 & & 78 & 62 & & 115 & 157508 & & 109 & 0.03 & \\
\hline
\end{tabular}

${ }^{*} P \leq 0.05 ; * * P \leq 0.01 ; * * * P \leq 0.001$.

in both generations and this difference is significant when considering cumulative inbreeding depression (Fig. 4). Such a decrease in inbreeding depression could come from purging the genetic load, from the fixation of deleterious alleles by drift (Barrett $\&$ Charlesworth, 1991; Groom \& Preuninger, 2000; Crnokrak \& Barrett, 2002) or from an adaptation to the glasshouse environment. Fitness of cross-pollinations was significantly larger in $\mathrm{F}_{2}$ than in $\mathrm{F}_{1}$ (paired tests within families) and could indicated that plants got adapted to the glasshouse environment, which might result in a decrease in the magnitude of inbreeding depression. To further discriminate between purging and drift, we compared the fitness of progeny from self-pollinations in $\mathrm{F}_{1}$ followed by crosspollinations in $\mathrm{F}_{2}(S C)$ and progeny coming from two generations of cross-pollinations (CC). If purging has occurred $S C$ individuals should have a higher fitness than $C C$ ones. Number of seeds per fruit was significantly larger for $S C$ than for $C C$ progeny (one-sided paired Wilcoxon signed rank test, d.f. $=37, P<0.05)$. How- ever, the 'signature' of purging was not detected for any other traits. Thus, it is likely that both purging and drift have occurred in our experiment. This might come from experimental constrains because the number of families dropped as the experiment proceeded. In generation $\mathrm{F}_{1}$, some selfed individuals never reached maturity and we used among the first flowering selfed individuals to successfully perform the $\mathrm{F}_{2}$ generation. This might have induced among and within family purging, respectively. In generation $\mathrm{F}_{2}$, we omitted 15 of 45 families; those producing viable seeds only for one level of inbreeding. This resulted in the loss of $50 \%$ of families between the two generations and is likely to be partly the cause of the decrease in the intensity of inbreeding depression between generation $F_{1}$ and $F_{2}$.

\section{The detection of synergistic epistasis}

Our results show that fitness decreases between outbred $(F \geq 0)$ and inbred individuals $(F \geq 0.5$ and $F \geq 0.75)$ but 


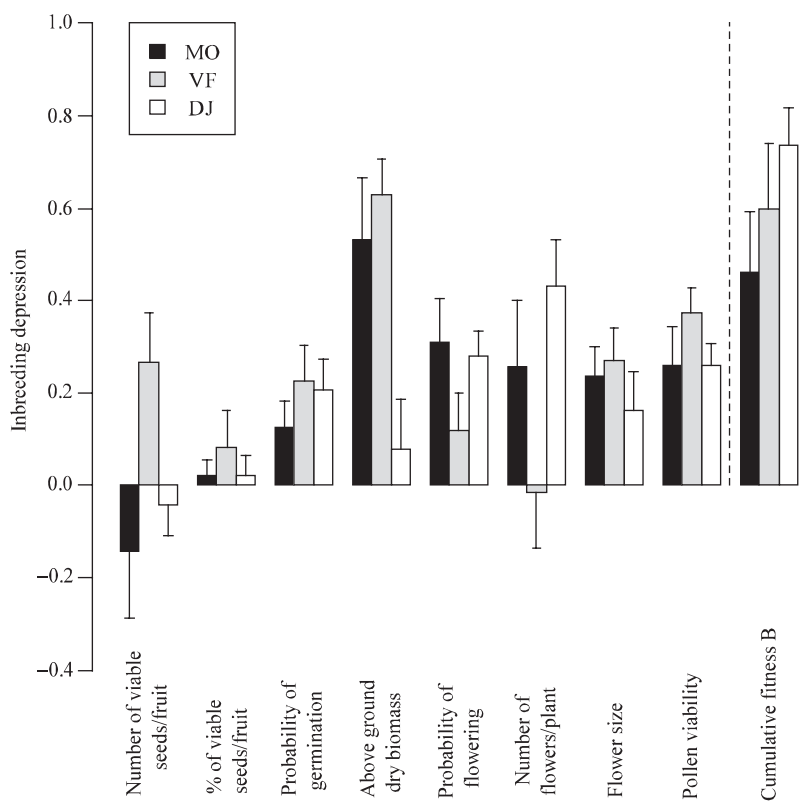

Fig. 3 Mean family inbreeding depression (+SE) along the life-cycle stages in Silene vulgaris (generation $\mathrm{F}_{2}$ ). Cumulative fitness B is the product of fruit set, the number of viable seeds per fruit, the probability of germination, the probability of flowering, the number of flowers per plant, the number of pollen grains per stamen and pollen viability.

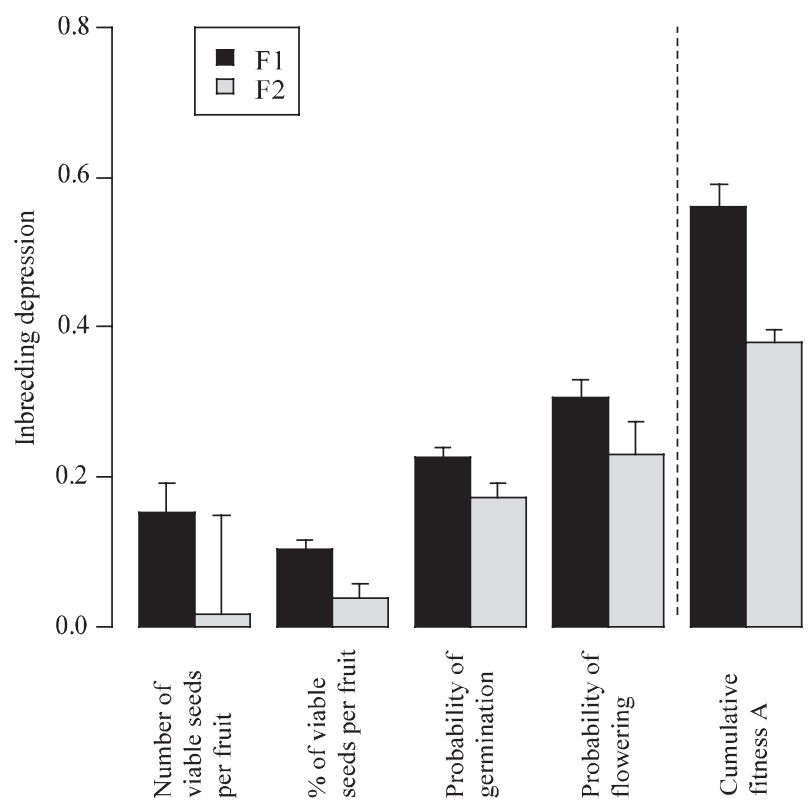

Fig. 4 Mean inbreeding depression over three populations (+SE) for generation $F_{1}$ (black) and generation $F_{2}$ (grey) in Silene vulgaris. Cumulative fitness $\mathrm{A}$ is the product of the fruit set, the number of viable seeds per fruit, the probability of germination and the probability of flowering. there was no significant fitness decrease between inbred progeny $(F \geq 0.5$ and $F \geq 0.75)$ (Table 2$)$, suggesting diminishing epistasis and/or purging. When testing for epistasis, the quadratic coefficient of the polynomial regression of log-transformed fitness on inbreeding levels $(F)$ was never significant. This could come from large variation in fitness observed among inbred individuals (Table 2), which might be due to the occurrences of purging and genetic drift. The power to detect a significant quadratic term given the observed mean difference and our sample size was $40 \%$ or less. Thus, a larger sample size might have allowed the detection of antagonistic epistasis.

Despite the importance of synergistic epistasis for the evolution of mating systems highlighted in theoretical investigations (Charlesworth, 1990), experimental studies performing successive generations of self- and crossfertilization generally found little evidence for synergistic epistasis. McCall et al. (1994) were unable to detect synergistic epistasis in Impatiens capensis. They argue that experimental constrains inducing purging and drift might have prevented the detection of synergistic epistasis. Willis (1993) detected weak synergistic epistasis for pollen viability; one of the four traits affected by inbreeding in his study of Mimulus guttatus. In the same species, Dudash et al. (1997) were unable to detect synergistic epistasis at the population level. However, they found both antagonistic and synergistic epistasis at the level of families and argued that such variation might impede the detection of synergistic epistasis at population levels. Similarly, Koelewijn (1998) found a significant interaction between inbreeding level and maternal families in the gynodioecious Plantago coronopus. In our study, interaction between levels of inbreeding and family was never significant, suggesting that the expression of inbreeding depression among families was not influenced by epistasis. Finally, Koelewijn (1998) detected synergistic interactions between loci for probability of flowering, however only under field conditions. As the expression of the genetic load is influenced by the environment, natural conditions may increase the probability to detect synergistic epistasis compared with glasshouse conditions. Thus, to increase the likelihood to detect synergistic epistasis, experiments should minimize purging, use different environmental conditions and explore the family and population levels.

\section{Maintaining gynodioecy}

Inbreeding depression for fitness traits was, although not always significant, variable from one population to another (Figs 2 and 3). Despite this variability and the differences in the spatial structure of populations, cumulative inbreeding depression was very similar between the three populations. This result could be the consequence of a restricted neighbourhood size since gene flow occurs at a local scale (Pettersson, 1992; McCauley, 
1998; Taylor et al., 1999). The opportunity for inbred matings and the intensity of cumulative inbreeding depression detected in this study could on their own explain the maintenance of females even under nuclear sex determinism. Whether the intensity of inbreeding depression can explain the maintenance of females within natural populations needs further investigations. In natural environments, conditions are generally harsher than in a glasshouse and the magnitude of inbreeding depression is often larger (Johnston, 1992; Wolfe, 1993; Cheptou et al., 2000; Hayes et al., 2005). However, comparative data exploring the variations in the intensity of inbreeding depression across different environments show that the difference in the strength of inbreeding depression is unpredictable because inbreeding depression of different lineages are uncorrelated across environments (Keller \& Waller, 2002; Armbruster $\delta$ Reed, 2005). Thus, the intensity of inbreeding in its natural habitat cannot be inferred from a glasshouse experiment and only a field experiment using the same families could detect possible differences in the intensity of inbreeding depression under a natural and a glasshouse environment.

We showed that fitness traits were more strongly affected by inbreeding in late life-cycle stages than in early ones. We detected some purging and argue that also drift, adaptation to the glasshouse environment and/or experimental constrains are likely the causes of the decrease in the magnitude of inbreeding depression observed between both generations. However, inbreeding depression at late life-cycle stages, thought to come from the effect of mildly deleterious alleles with partial dominance is less likely purged than at early stages (Husband \& Schemske, 1996). Thus, inbreeding depression at late stages of the life cycle might always remain at high levels.

Moreover, in S. vulgaris the progeny of self-fertilized hermaphrodites often display a biased female sex ratio (Emery \& McCauley, 2002). In our study, two-thirds of the families also showed this tendency. The proportion of hermaphrodites was around $100 \%$ and $80 \%$ in the progeny of cross- and self-fertilized hermaphrodites, respectively. Importantly, female and hermaphrodite selfed offspring did not differ in their fitness components and thus sex ratio differences between inbreeding levels was not a confounding effect. A more detailed investigation of the sex ratio differences among inbreeding levels will be given elsewhere. However, the appearance of females in the progeny of selfed hermaphrodites is important because it will prevent successive generations of self-fertilization and might impede the purging process.

In conclusion, a combination of inbreeding depression at late stages of the life cycle and female-biased sex ratio in progeny of self-fertilized hermaphrodites may limit the purging of deleterious alleles and help to maintain females in gynodioecious populations of $S$. vulgaris.

\section{Acknowledgments}

The authors thank Loïc Degen, Mailyn A. Gonzalez, Hélène Jaccard, Mélanie Quennoz, Isabelle Py, Myriam Vogel and Laurent Vuataz for help in the glasshouse; Spencer C. H. Barrett, Giorgina Bernasconi, Pierre Fontanillas, Luc D. B. Gigord, Lukas F. Keller, David E. McCauley, Christian Parisod and Nicolas Perrin for helpful comments on previous versions of the manuscript. Financial support was provided by the Société Académique Vaudoise (grant to M.G.), by the Roche Research Foundation (grant to M.G.) and by the Swiss National Science Foundation (grant no. PBLAA-109434 to M.G. and grant no. 3100-05945.98 to J.G.).

\section{References}

Ågren, J. \& Schemske, D.W. 1993. Outcrossing rate and inbreeding depression in two annual monoecious herbs, Begonia hirsuta and B. semiovata. Evolution 47: 125-135.

Armbruster, P. \& Reed, D.H. 2005. Inbreeding depression in benign and stressful environments. Heredity 95: 235-242.

Atlan, A., Gouyon, P.-H., Fournial, T., Pomente, D. \& Couvet, D. 1992. Sex allocation in an hermaphroditic plant: the case of gynodioecy in Thymus vulgaris L. J. Evol. Biol. 5: 189-203.

Barrett, S.C.H. \& Charlesworth, D. 1991. Effects of a change in the level of inbreeding on the genetic load. Nature 352: 522-524.

Carr, D.E. \& Dudash, M.R. 1997. The effects of five generations of enforced selfing on potential male and female function in Mimulus guttatus. Evolution 51: 1797-1807.

Charlesworth, B. 1990. Mutation-selection balance and the evolutionary advantages of sex and recombination. Genet. Res. 55: 199-221.

Charlesworth, D. 1999. Theories of the evolution of dioecy. In: Gender and Sexual Dimorphism in Flowering Plants (M. A. Gerber, T. E. Dawson \& L. F. Delph, eds), pp. 33-60. Springer-Verlag, Berlin.

Charlesworth, D. \& Charlesworth, B. 1987. Inbreeding depression and its evolutionary consequences. Annu. Rev. Ecol. Syst. 18: $237-268$.

Charlesworth, D. \& Ganders, F.R. 1979. The population genetics of gynodioecy with cytoplasmic-genic male-sterility. Heredity 43: $213-218$.

Charlesworth, D. \& Laporte, V. 1998. The male-sterility polymorphism of Silene vulgaris: analysis of genetic data from two populations and comparison with Thymus vulgaris. Genetics 150: 1267-1282.

Charlesworth, B., Morgan, M.T. \& Charlesworth, D. 1991. Multilocus models of inbreeding depression with synergistic selection and partial self-fertilization. Genet. Res. 57: 177-194.

Cheptou, P.-O., Imbert, E., Lepart, J. \& Escarre, J. 2000. Effects of competition on lifetime estimates of inbreeding depression in the outcrossing plant Crepis sancta (Asteraceae). J. Evol. Biol. 13: $522-531$

Couvet, D., Ronce, O. \& Gliddon, C. 1998. The maintenance of nucleocytoplasmic polymorphism in a metapopulation: the case of gynodioecy. Am. Nat. 152: 59-70.

Crnokrak, P. \& Barrett, S.C.H. 2002. Perspective: purging the genetic load: a review of the experimental evidence. Evolution 56: 2347-2358. 
Crow, J.F. \& Kimura, M. 1970. An Introduction to Population Genetics Theory. Harper \& Row, New York.

Dafni, A. 1992. Pollination Ecology: A Practical Approach. Oxford University Press, Oxford.

Darwin, C. 1877. Different Forms of Flowers on Plants of the Same Species. John Murray, London.

Dudash, M.R., Carr, D.E. \& Fenster, C.B. 1997. Five generations of enforced selfing and outcrossing in Mimulus guttatus: inbreeding depression variation at the population and family level. Evolution 51: 54-65.

Emery, S.N. \& McCauley, D.E. 2002. Consequences of inbreeding for offspring fitness and gender in Silene vulgaris, a gynodioecious plant. J. Evol. Biol. 15: 1057-1066.

Gigord, L.D.B., Lavigne, C., Shykoff, J.A. \& Atlan, A. 1999. Evidence for effects of restorer genes on males and female reproductive functions of hermaphrodites in the gynodioecious species Thymus vulgaris L. J. Evol. Biol. 12: 596-604.

Groom, M.J. \& Preuninger, T.E. 2000. Population type can influence the magnitude of inbreeding depression in Clarkia concinna (Onagraceae). Evol. Ecol. 14: 155-180.

Hayes, N.C., Winsor, J.A. \& Stephenson, A.G. 2005. Environmental variation influences the magnitude of inbreeding depression of Cucurbita pepo ssp. texana (Cucurbitaceae). J. Evol. Biol. 18: 147-155.

Husband, B.C. \& Schemske, D.W. 1996. Evolution of the magnitude and timing of inbreeding depression in plants. Evolution 50: 54-70.

Johnston, M.O. 1992. Effects of cross and self-fertilization on progeny fitness in Lobelia cardinalis and L. siphilitica. Evolution 46: $688-702$

Johnston, M.O. \& Schoen, D.J. 1994. On the measurment of inbreeding depression. Evolution 48: 1735-1741.

Jolls, C.L. \& Chenier, T.C. 1989. Gynodioecy in Silene vulgaris (Caryophyllaceae): progeny success, experimental design and maternal effects. Am. J. Bot. 76: 1360-1367.

Karron, J.D., Mitchell, R.J., Holmquist, K.G., Bell, J.M. \& Funk, B. 2004. The influence of floral display size on selfing rates in Mimulus ringens. Heredity 92: 242-248.

Keller, L.F. \& Waller, D.M. 2002. Inbreeding effects in wild populations. Trends Ecol. Evol. 17: 231-241.

Kesseli, R. \& Jain, S.K. 1984. An ecological genetic study of gynodioecy in Limnanthes douglasii (Limnanthaceae). Am. J. Bot. 71: 775-786.

Kobayashi, S., Inoue, K. \& Kato, M. 1997. Evidence of pollen transfer efficiency as the natural selection factor favouring a large corolla of Campanula punctata pollinated by Bombus diversus. Oecologia 111: 535-542.

Koelewijn, H.P. 1998. Effects of different levels of inbreeding on progeny fitness in Plantago coronopus. Evolution 52: 692702 .

Kohn, J.R. \& Biardi, J.E. 1995. Outcrossing rates and inferred levels of inbreeding depression in gynodioecious Cucurbita foetidissima (Cucurbitaceae). Heredity 75: 77-83.

Lande, R. \& Schemske, D.W. 1985. The evolution of selffertilization and inbreeding depression in plants. I. Genetic models. Evolution 39: 24-40.

Lewis, D. 1941. Male sterility in natural populations of hermaphrodite plants. The equilibrium between females and hermaphrodites to be expected with different types of inheritance. New Phytol. 40: 56-63.

Lloyd, D.G. 1976. The transmission of genes via pollen and ovules in gynodioecious angiosperms. Theor. Popul. Biol. 9: 299-316.

Lynch, M. 1988. Design and analysis of experiments on random drift and inbreeding depression. Genetics 120: 791-807.

Manly, B.F.J. 1997. Randomization, Bootstrap and Monte Carlo Methods in Biology, 2nd edn. Chapman \& Hall, London.

Mayer, S.S., Charlesworth, D. \& Meyers, B. 1996. Inbreeding depression in four populations of Collinsia heterophylla nutt (Scrophulariaceae). Evolution 50: 879-891.

McCall, C., Waller, D.M. \& Mitchell-Olds, T. 1994. Effects of serial inbreeding on fitness components in Impatiens capensis. Evolution 48: 819-827.

McCauley, D.E. 1998. The genetic structure of a gynodioecious plant: nuclear and cytoplasmic genes. Evolution 52: 255260.

Melser, C., Bijeveld, A. \& Klinkhamer, P.G. 1999. Late-acting inbreeding depression in both male and female function of Echium vulgare (Boraginaceae). Heredity 83: 162-170.

Mutikainen, P. \& Delph, L.F. 1998. Inbreeding depression in gynodioecious Lobelia siphilitica: among-family differences override between-morph differences. Evolution 52: 15721582 .

Pettersson, M.W. 1992. Advantages of being a specialist female in gynodioecious Silene vulgaris (Caryophyllaceae). Am. J. Bot. 79: 1389-1395.

R Development Core Team. 2003. R: A language and Environment for Statistical Computing. R Foundation for Statistical Computing, Vienna, Austria. Available at: http://www. R-project.org.

Sakai, A.K., Weller, S.G., Chen, M.-L., Chou, S.-Y. \& Tasanont, C. 1997. Evolution of gynodioecy and maintenance of females: the role of inbreeding depression, outcrossing rates and resource allocation in Schiedea adamantis (Caryophyllaceae). Evolution 51: 724-736.

Shykoff, J.A., Bucheli, E. \& Kaltz, O. 1997. Anther smut disease in Dianthus sylvestris (Caroyphyllaceae): natural selection on floral traits. Evolution 51: 383-392.

Shykoff, J.A., Kolokotronis, S.-O., Collin, C.L. \& LopezVillavicencio, M. 2003. Effects of male sterility on reproductive traits in gynodioecious plants: a meta-analysis. Oecologia 135: $1-9$

Taylor, D.R., Trimble, S. \& McCauley, D.E. 1999. Ecological genetics of gynodioecy in Silene vulgaris: relative fitness of females and hermaphrodites during the colonization process. Evolution 53: 745-751.

Vaughton, G. \& Ramsey, M. 1998. Floral display, pollinator visitation and reproductive success in the dioecious perennial herb Wurmbea dioica (Liliaceae). Oecologia 115: 93-101.

Willis, J.H. 1993. Effects of different levels of inbreeding on fitness components in Mimulus guttatus. Evolution 47: 864-876.

Wolfe, L.M. 1993. Inbreeding depression in Hydrophyllum appendiculatum: role of maternal effects, crowding, and parental mating history. Evolution 47: 374-386.

Received 17 January 2006; revised 3 April 2006; accepted 5 April 2006 